\title{
Severe epithelial hyperplasia as a complication of a novel biodegradable stent
}

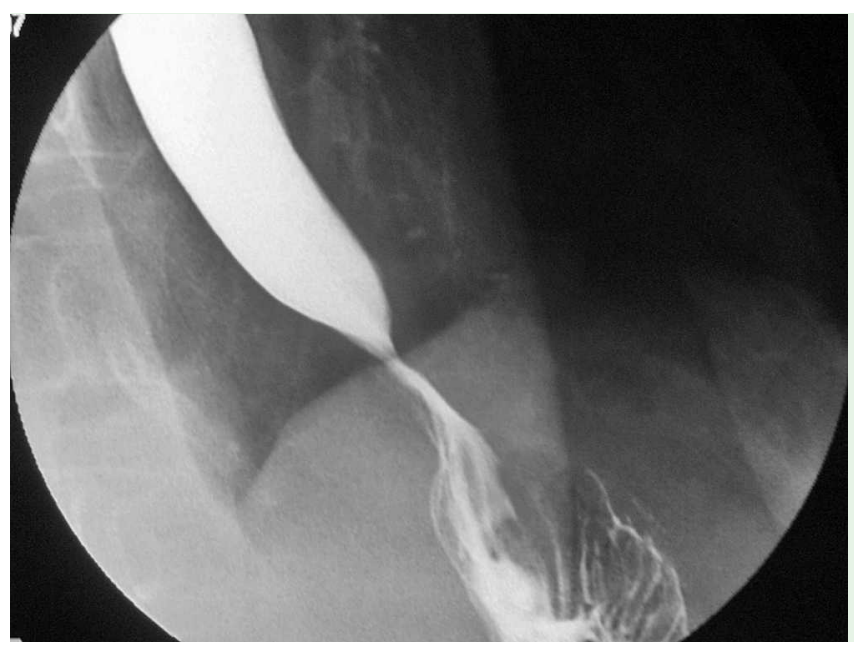

Fig. 1 Severe stricture of the surgical anastomosis.

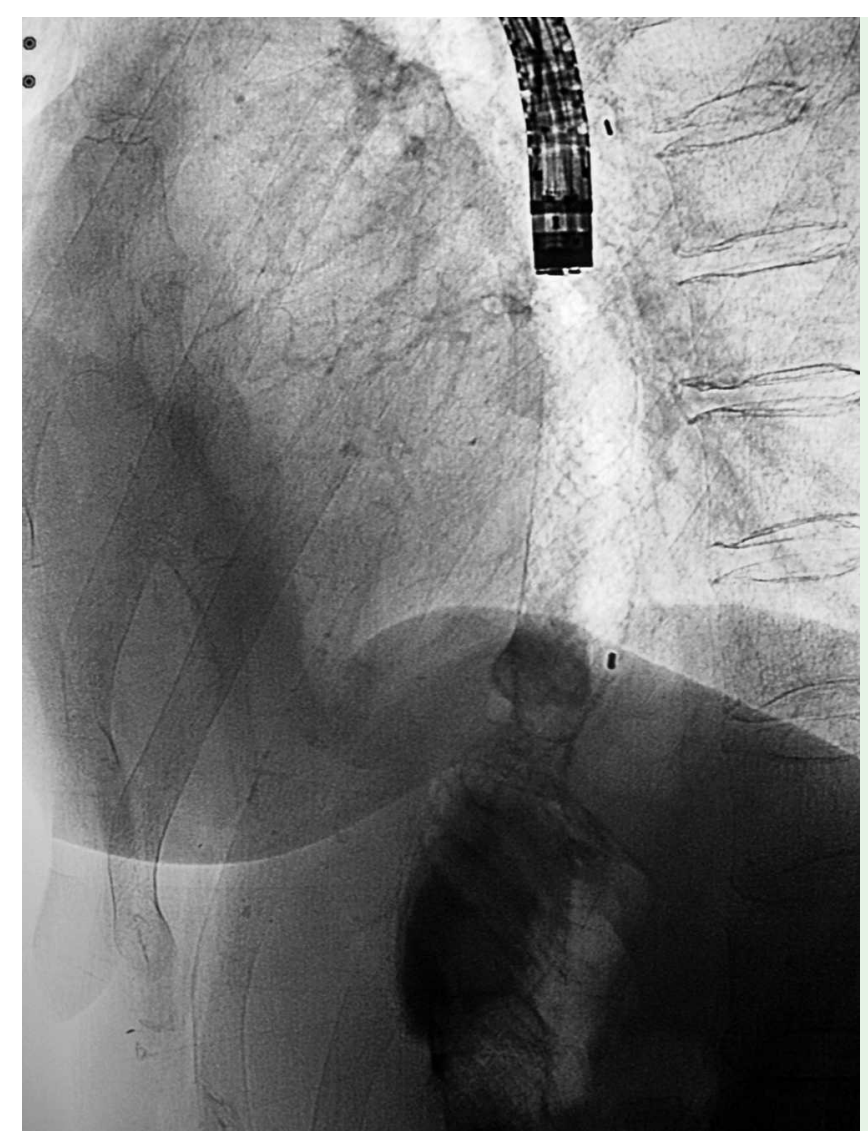

Fig. 2 Stent placement.

A 56-year-old woman with a total gastrectomy and an esophagojejunal anastomosis developed a severe stricture of the surgical anastomosis ( $\bullet$ Fig. 1).

The stricture was radiologically dilated, resulting in perforation during the dilation maneuvers. The perforation was re- solved nonsurgically. The stricture recurred, so we placed a covered metal stent that was removed after 2 months, but the stricture recurred again afterwards.

In this situation, we decided to place the SX-Ella-BD (Ella-CS, s. r. o., Hradec Králové, Czech Republic) - a new polydioxanone

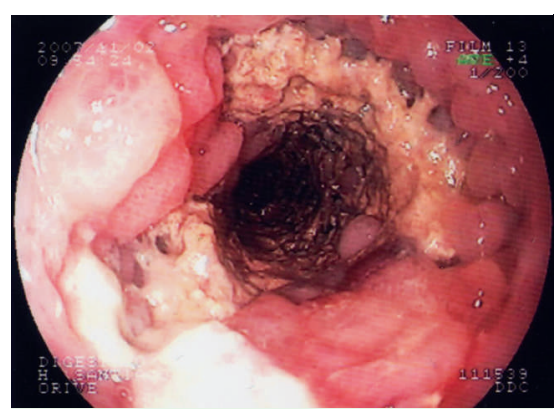

Fig. 3 Inflammatory tissue developing.

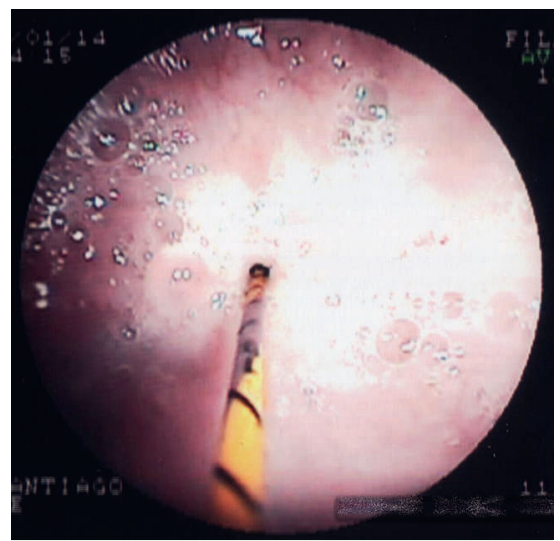

Fig. 4 New stricture caused by inflammatory tissue hyperplasia that developed within the proximal end of the stent 14 weeks after the stent was placed.

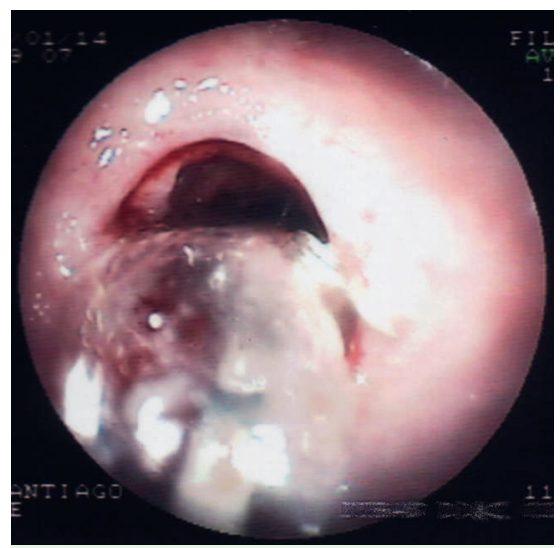

Fig. 5 Dilation of the stenosis.

(PDS) biodegradable stent - under radiologic and endoscopic guidance ( $\bullet$ Fig. 2). Three months later the patient attended complaining of progressive dysphagia. Endoscopy revealed that the stent had already degraded, and a new severe stricture caused by hyperplastic inflammatory tissue was found at the level corresponding to the position of the proximal end of the stent ( $\bullet$ Fig. 3 and 4).

The first (postsurgical) stricture now had a slightly larger diameter than before the stent placement. The hyperplasia was 
successfully dilated endoscopically (๑ Fig. 5).

The dysphagia disappeared after dilation of the hyperplastic stricture.

It is assumed that the biocompatibility characteristics of the new biodegradable stents may avoid the risk of developing new hyperplastic strictures better than the commonly used self-expanding plastic (SEPS) and metal stents (SEMS) [1 - 5]. We report the development in our patient of severe epithelial hyperplasia as a complication of a novel biodegradable stent. This new stricture was treated effectively with balloon dilation. To our knowledge, this is the first case in which this complication has been reported in association with this kind of biodegradable stent.

Despite the effectiveness of biodegradable stents in dilating strictures, and even despite their being theoretically biocompatible, they may not be able to confer exemption from the development of hyperplastic strictures. The hyperplasia was easily and successfully dilated. Further studies are needed to determine the real effectivity and safety of this stent.
Endoscopy_UCTN_Code_CPL_1AJ_2AF

\section{A. Orive-Calzada, M. Álvarez-Rubio, S. Romero-Izquierdo, M. Cobo Martin, J. F. Juanmartiñena, M. Ogueta-Fer- nández, E. Molina-Álvarez, L. Eraña- Ledesma}

Gastroenterology and Hepatology, Hospital Santiago Apóstol, C/Olaguibel 29, Vitoria-Gasteiz, Alava, Spain

\section{References}

1 Ackroyd R, Watson DI, Devitt PG, Jamieson GG. Expandable metallic stents should not be used in the treatment of benign esophageal strictures. J Gastroenterol Hepatol 2001; 16: 484-487

2 Song HY, Jung HY, Park SI et al. Covered retrievable expandable nitinol stents in patients with benign esophageal strictures: initial experience. Radiology 2000; 217: 551-557

3 Barthel JS, Kelley ST, Klapman JB. Management of persistent gastroesophageal anastomotic strictures with removable self-expandable polyester silicon-covered (Polyflex) stents: an alternative to serial dilation. Gastrointes endosc 2008; 67: 546-552
4 Zilberman M, Nelson KD, Eberhart RC. Mechanical properties and in vitro degradation of bioresorbable fibers and expandable fiber-based stents. J Biomed Mater Res B Appl Biomater 2005; 74: $792-799$

5 Tanaka T, Takahashi $M$, Nitta $N$ et al. Newly developed biodegradable stents for benign gastrointestinal tract stenoses: a preliminary clinical trial. Digestion 2006; 74: 199205

Bibliography

DOI 10.1055/s-0029-1214599

Endoscopy 2009; 41: E137-E138

(C) Georg Thieme Verlag KG Stuttgart · New York . ISSN 0013-726X

\section{Corresponding author}

\section{A. Orive-Calzada, MD}

Gastroenterology and Hepatology

Hospital Santiago Apóstol

C/Olaguibel 29

Vitoria-Gasteiz

Alava 01004

Spain

Fax: +34-945-007600

aitor_orive@yahoo.com 